\title{
MAGNESIUM SULFATE ATTACK RESISTANCE OF SCM-MODIFIED CEMENT-BASED MATERIALS
}

\author{
YANG WANG*, "YONG GE*, XIAOWEI WANG**, XIN CHEN*, ${ }^{*}$ QINFEI LI***, ****, "YONGQUAN ZHANG***** \\ *School of Transportation Science and Engineering, Harbin Institute of Technology, \\ Harbin, 150090, P. R. China \\ **UJN \& Vree Joint Research Institute of New Materials Engineering \& Technology, \\ Tsingtao, P. R. China \\ ***Shandong Provincial Key Laboratory of Preparation and Measurements of Building Materials, University of Jinan, \\ Jinan, 250022, P. R. China \\ ****State Key Laboratory of Green Building Materials, \\ Beijing, 100024, P. R. China \\ *****Department of Road Engineering, Transportation Institute, Inner Mongolia University, \\ Hohhot, 010070, P. R. China \\ "E-mail: hitbm@163.com; mse_liqf@ujn.edu.cn; zyqzygzs@imu.edu.cn
}

Submitted April 7, 2021; accepted May 18, 2021

Keywords: Sulfate attack resistivity, Supplementary cementitious materials, Nano silica, Mechanical properties

\begin{abstract}
Sulfate attack is one of the main concerns of cement-based materials. In this research, the magnesium sulfate attack resistivity of cement-based materials modified with nano silica (NS) and supplementary cementitious materials (SCMs) i.e., silica fume (SF), fly ash (FA) and ground granulated blast-furnace slag (GGBS) was studied up to 500 days. The effects of the initial curing time (7 and 28 days) on the mechanical property and volume stability of the cement mortars under magnesium sulfate attack were studied. The results showed that the NS has a better capability of improving the magnesium sulfate attack resistivity of the cement mortar compared with traditional supplementary materials, and a longer initial curing time contributed to the higher resistivity. The higher pozzolanic reactivity of NS led to a denser structure of the cement mortar and retarded the magnesium sulfate attack process. FA-added samples had poor resistance to magnesium sulfate attack due to the low pozzolanic reactivity. The resistance of the GGBS-added samples to magnesium sulfate attack was moderate among the samples.
\end{abstract}

\section{INTRODUCTION}

Cement-based materials are the most widely used building materials in the world, and their durability has a significant impact on the service life of concrete structures. Sulfate attack, such as $\mathrm{Na}_{2} \mathrm{SO}_{4}$ and $\mathrm{MgSO}_{4}$ attacks, is one of the most important factors affecting the durability of concrete $[1,2]$. Sulfate ions react with the hydration products $(\mathrm{CH}, \mathrm{C}-\mathrm{S}-\mathrm{H}$ gel $)$ of the cement, generating gypsum, or react with $\mathrm{C}_{3} \mathrm{~A}$ or monosulfate $(\mathrm{AFm})$, forming ettringite (AFt), both of which will generate expansion and even lead to micro/macro-cracks $[3,4] . \mathrm{A} \mathrm{MgSO}_{4}$ attack will also generate gypsum and ettringite. Moreover, the magnesium ion can also react with $\mathrm{Ca}(\mathrm{OH})_{2}$ to form $\mathrm{Mg}(\mathrm{OH})_{2}$, or react with the $\mathrm{C}-\mathrm{S}-\mathrm{H}$ gel to form M-S-H with no binding force, all of which contribute to the deterioration of cement-based materials [5-7].

To improve the sulfate attack resistivity of cementbased materials, reducing the corrosive constituent, such as the $\mathrm{C}_{3} \mathrm{~A}$ content [8] or lowering the water-to-binder ratio has been applied $[9,10]$. Comparatively, the addition of supplementary cementitious materials ( $\mathrm{SCMs}$ ) is broadly used. Haufe [10] and Bassuoni [11] found that fly ash (FA) and granulated blast furnace slag (GGBS) can reduce the porosity, as well as the pore size of hardened cementitious materials by taking advantage of their pozzolanic reactivity with calcium hydroxide from cement hydration. Meanwhile, the content of $\mathrm{C}_{3} \mathrm{~A}$ can also be reduced due to the replacement of the cement, all of which contribute to the improvement in the sulfate attack resistivity. Other SCMs of various pozzolanic reactivities, such as silica fume (SF) and metakaolin (MK), showed similar effects on the sulfate attack resistivity due to their effects on reducing the $\mathrm{Ca}(\mathrm{OH})_{2}$ and modifying the physicochemical properties of the microstructures [12-16].

However, the relatively low chemical reactivity of SCMs compared to cement, especially at the early ages $[5,17]$, contributes weakly to the development of the properties. Thus, the relatively mature development of the properties/microstructure of cementitious materials before suffering a sulfate attack would be desired. In recent years, some researchers have shown that nano silica (NS) has a very high pozzolanic reactivity which will significantly improve the microstructure and performan- 
ce of cement-based materials at the very early ages even at small dosages [18-22]. The results showed that NS can effectively improve the performance of cement-based materials even after a short initial curing time [23-25], which hinted at its potential of being used to improve the sulfate attack resistivity of cementitious materials.

In this study, the effects of SCMs with different reactivities (nano silica, silica fume, fly ash and ground granulated blast furnace slag) on the sulfate attack resistivity were investigated and compared to fill the gap of understanding the differences in the sulfate attack resistance performance under magnesium sulfate environments $\left(\mathrm{MgSO}_{4}\right)$ and maturity ( 7 and 28 days of initial curing) for the exploration of better sulfate attack resistivity of cementitious materials.

\section{EXPERIMENTAL}

Materials

In this study, Portland cement (P.I 42.5, complying to EU CEM I 42.5 according to EN 197-1 (2000)), nano silica (NS), silica fume (SF), ground granulated blast furnace slag (GGBS), and class F fly ash (FA) were used. The chemical compositions of the raw materials are shown in Table 1.

Table 1. Chemical compositions of the cement, NS, SF, FA and GGBS (wt. \%).

\begin{tabular}{lrcccccc}
\hline & $\mathrm{CaO}$ & $\mathrm{SiO}_{2}$ & $\mathrm{Al}_{2} \mathrm{O}_{3}$ & $\mathrm{SO}_{3}$ & $\mathrm{Fe}_{2} \mathrm{O}_{3}$ & $\mathrm{MgO}$ & LOI \\
\hline $\mathrm{P} \cdot \mathrm{I}$ & 64.65 & 21.88 & 4.49 & 2.44 & 3.45 & 2.36 & 0.73 \\
$\mathrm{SF}$ & 0.12 & 98.08 & 0.34 & 0.42 & 0.04 & 0.34 & 0.66 \\
FA & 4.00 & 50.04 & 35.21 & 1.52 & 5.38 & 0.54 & 3.31 \\
GGBS & 30.20 & 32.78 & 17.55 & 2.30 & 1.45 & 6.36 & 9.36 \\
$\mathrm{NS}$ & - & $\geq 98.0$ & - & - & - & - & - \\
\hline
\end{tabular}

\section{Sample preparation and test methods}

In this study, mortar samples were prepared at a $w / b$ ratio of 0.35 , and the mix proportions are shown in Table 2 . The mortar samples were prepared according to the Chinese standard GB/T 17671-1999 [26] at a sand-to-cement ratio of $3: 1$. The NS was dispersed in water by ultra-

Table 2. Mix proportions of the mortars.

\begin{tabular}{lcccccc}
\hline Samples & Cement & NS & SF & FA & GGBS & $\begin{array}{c}\text { Superplasticizer } \\
\text { (wt. \% of binder) }\end{array}$ \\
\cline { 2 - 6 } & \multicolumn{9}{c}{ (wt. \%) } & & 0.20 \\
\hline C & 100 & - & - & - & - & 0.40 \\
NS1 & 99 & 1 & - & - & - & 0.80 \\
NS3 & 97 & 3 & - & - & - & 0.16 \\
SF5 & 95 & - & 5 & - & - & 0.14 \\
SF10 & 90 & - & 10 & - & - & 0.15 \\
FA10 & 90 & - & - & 10 & - & 0.10 \\
FA30 & 70 & - & - & 30 & - & 0.17 \\
GGBS10 & 90 & - & - & - & 10 & 0.15 \\
GGBS30 & 70 & - & - & - & 30 & \\
\hline
\end{tabular}

sonic dispersion for 10 min prior to being added into the binders. After mixing for $4 \mathrm{~min}$, the mortar was cast into moulds with dimensions of $160 \times 40 \times 40 \mathrm{~mm}$ and $285 \times 25 \times 25 \mathrm{~mm}$. The samples were moved into a standard curing room $\left(20 \pm 3{ }^{\circ} \mathrm{C}\right.$, Relative Humidity $(\mathrm{RH})$ $\geq 95 \%$ ) after being demoulded one day later and then were cured for certain periods before the sulfate attack experiment, i.e., moving into 5 wt. $\% \mathrm{MgSO}_{4}$ solutions for $7,28,180,500$ days, respectively. During these periods, the solution was replaced every 30 days.

\section{Test methods}

\section{Mechanical property measurements and linear expansion}

The mechanical properties and linear expansion of the cement mortar were measured according to Chinese standard GB/T 17671-1999 [26] and ASTM C1012 [27], respectively.

\section{Pozzolanic reactivity}

The $\mathrm{CH}$-consuming rate and capacities of $3 \% \mathrm{NS}$, 30 wt.\% FA, 10 wt.\% SF and 30 wt.\% GGBS were tested. The water-to-binder ratio was kept at 2.0. The NS and SCMs were mixed with $10 \mathrm{~g} \mathrm{Ca}(\mathrm{OH})_{2}$ for $5,16 \mathrm{~h}, 1$, 2, 3, 7 days, and then these samples were transferred into a $\mathrm{N}_{2}$-atmosphere glovebox and vacuum-oven dried at $50{ }^{\circ} \mathrm{C}$ for $48 \mathrm{~h}$ before measuring by Thermogravimetric analysis (TGA, Mettler-1600HT, Sweden) to analyse the $\mathrm{CH}$-consuming capability of the NS and SCMs.

\section{Scanning Transmission Microscopy (SEM) and Micro-computed tomography (MicroCT)}

Scanning Transmission Microscopy (SEM) images were collected by a ZEISS EVOLS15 equipped with an Energy Dispersive Spectrometer (Oxford X-MaxN). Micro-computed tomography (ZEISS Xradia 510 Versa) was used to observe the SF agglomeration in the SF-blended cement paste exposed to 5 wt. $\% \mathrm{MgSO}_{4}$ solution 180 days into the test. The voltage and the power were $80 \mathrm{keV}$ and $7 \mathrm{~W}$, respectively.

\section{RESULTS AND DISCUSSION}

Pozzolanic reactivity

Figure 1 presents the $\mathrm{Ca}(\mathrm{OH})_{2}$-consuming capability of the nano silica (NS), silica fume (SF), fly ash (FA) and granulated ground blast furnace slag (GGBS). The NS per gram consumed more $\mathrm{CH}$ than SF, while the SF also reacted more with the $\mathrm{CH}$ than the FA and GGBS, illustrating the high pozzolanic reactivity of the NS and silica fume. 


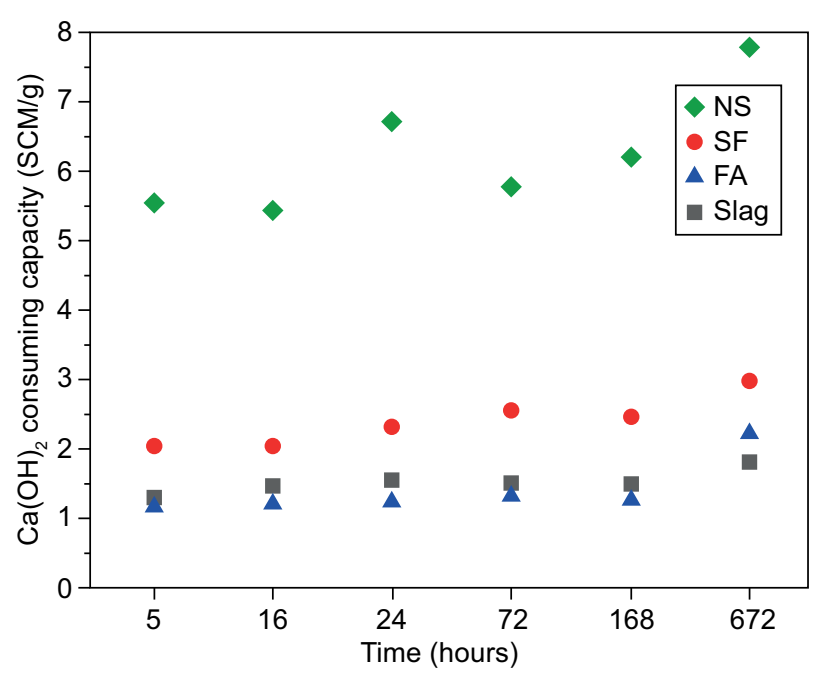

Figure 1. $\mathrm{CH}$ consuming capacity of per gram of the nano silica (NS), silica fume (SF), fly ash (FA) and granulated ground blast furnace slag (SLAG).

\section{Compressive strength}

vs. flexural strength

In this work, mortar specimens were standard-cured for 7-days/28-days and then immersed in a $5 \mathrm{wt} . \%$ magnesium sulfate solution for 7, 28, 180 and 500 days respectively. Mortar cured in a saturated $\mathrm{Ca}(\mathrm{OH})_{2}$ solution $(\mathrm{CH}-\mathrm{C})$ was also used for the control samples to understand the effects of the NS and SCMs on magnesium sulfate attack resistivity.

The development of the flexural strength of the cement mortars is shown in Figure 2. The flexural strength of the $\mathrm{CH}-\mathrm{C}$ specimens was slightly higher than those of the cement mortars cured in standard curing conditions $\left(20 \pm 3{ }^{\circ} \mathrm{C}, \mathrm{RH} \geq 95 \%\right)$ up to 500 days in the $\mathrm{MgSO}_{4}$ immersion, indicating that a beneficial contribution to the strength from the formation of hydration products under sulfate attack continued into this period, and similar results have been obtained by Wee T.H. et. al [28]. This was attributed to the fact that not enough examples of sulfate attack products (e.g., ettringite and gypsum) had been produced to cause damage to the mortar. Moreover, in the early stages of magnesium sulfate attack, the products filled the pores or cracks, making the mortar more structurally dense, thus showing an increase in strength. On the other hand, the sulfate solution promoted the hydration of the cement [29], which might also have a positive effect on the increase in the mortar strength.

As the immersion time increased to 180 days, the flexural strength of the NS-blended specimens was lower than that of the SF-blend ones. NS made the structure of the mortar denser, making it difficult for the sulfate to enter the interior of the hardened mortar. Consequently, fewer sulfate attack products were formed, and the strength growth rate was reduced due to the filling effect of the products in the sulfate environment. The strength of the SF-blended mortar specimens was higher than that of the NS, although SF and NS have similar silica content. The dosage of the SF was higher than that of the NS, resulting in a higher strength development. The FAblended specimens had a greater increase in the flexural strength under the sulfate attack due to the lower early activity of the FA.

The structure of the mortar specimens maintained for 7 days was not sufficiently mature to withstand the sulfate attack in a sulfate environment, forming more sulfate products and a denser structure with increased strength. At the same time, the sulfate had an activation

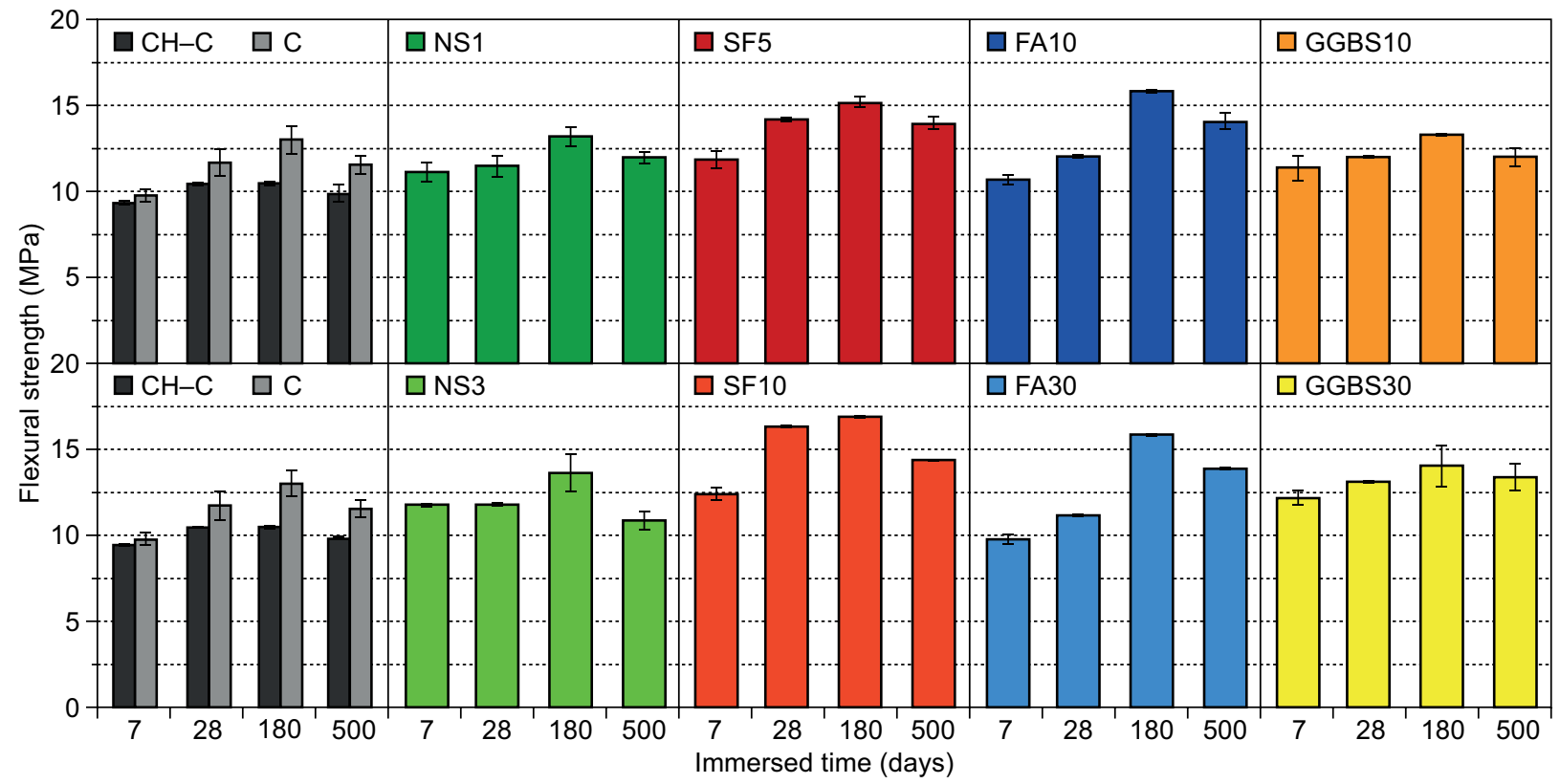

Figure 2. Flexural strength of the cement mortar samples cured in standard conditions for 7 days and then cured in a saturated $\mathrm{Ca}(\mathrm{OH})_{2}$ solution and a 5 wt. $\% \mathrm{Mg}_{2} \mathrm{SO}_{4}$ solution up to 500 days. 
effect on the reaction of the fly ash in the cement hydration system [29]. In addition, the sulfate attack is an outward to inward process, with the outer layer being the first to have undergone the sulfate reaction and, therefore, having a more pronounced effect in terms of the flexural strength. The higher the FA used, the higher the rate of the strength development under the sulfate reaction. However, the GGBS-blended mortars had less growth in the flexural strength under the sulfate attack. GGBS is more reactive than FA, which effectively reacted to densify the cement mortar structure in the early stages of hydration and reduced the sulfate intrusion. Meanwhile, the large amount of GGBS replaced part of the cement, reducing the amount of the hydration products sensitive to the sulfate attack, such as $\mathrm{CH}, \mathrm{AFm}$ and unhydrated $\mathrm{C}_{3} \mathrm{~A}$ [12]. The reduction in the flexural strength of all the specimens by 500 days indicated that the number of sulfate products generated had damaged the structure of the cement mortar, resulting in a reduction in the mechanical properties.

The results of the compressive strength are shown in Figure 3, which was consistent with the pattern of the flexural strength in Figure 2, the compressive strength gradually increased with an increase in the exposition time in the early stage, and the strength showed a decreasing trend when the time reached 500 days. At the same time, the NS group of specimens showed a certain strength decrease. It was inferred [9] that NS makes the mortar denser, causing an increase in the crystallisation pressure generated by the erosion products, which were prone to cracking and strength deterioration.

The strength of the SF-blended specimens showed a decreasing trend at 180 days due to the insufficient dispersion of the silica fume and agglomeration within the hydration system, and the erosion process caused the disintegration of the agglomerated silica fume and a decrease in the strength, as can be seen in Figure 4. The specimens blended with GGBS also showed a reduction in
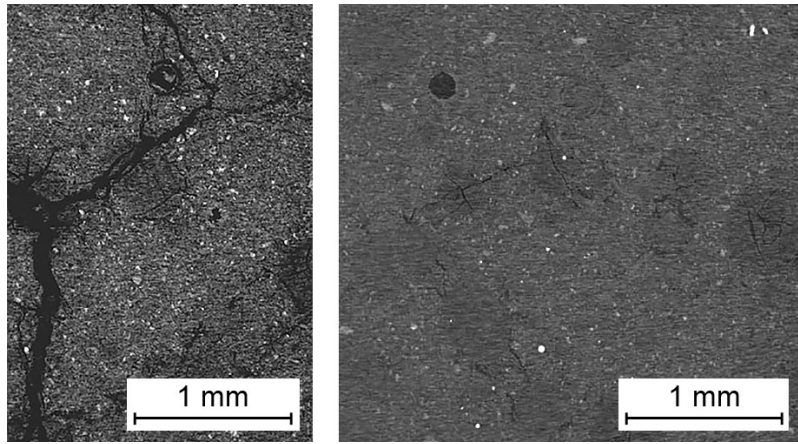

a) X-CT images of the SF-added samples

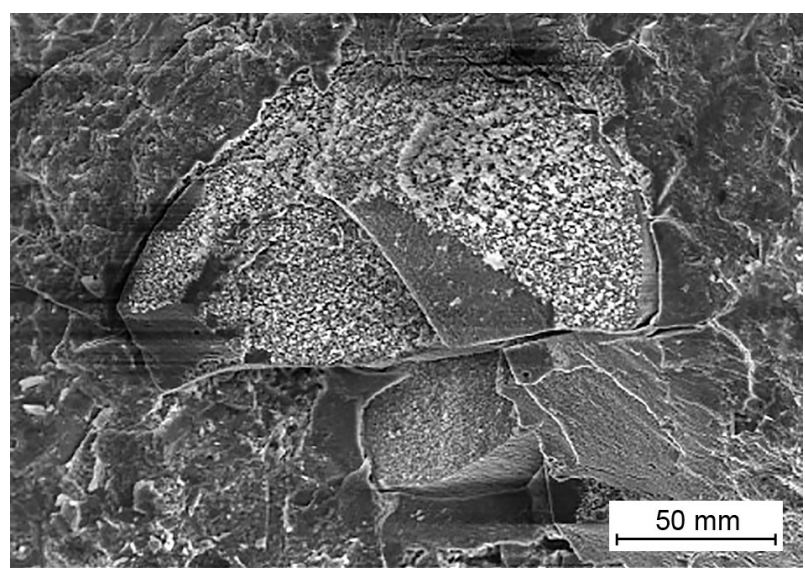

b) SEM image of the SF-added samples

Figure 4. Images of the agglomerated silica fume and disintegration under the sulfate attack.

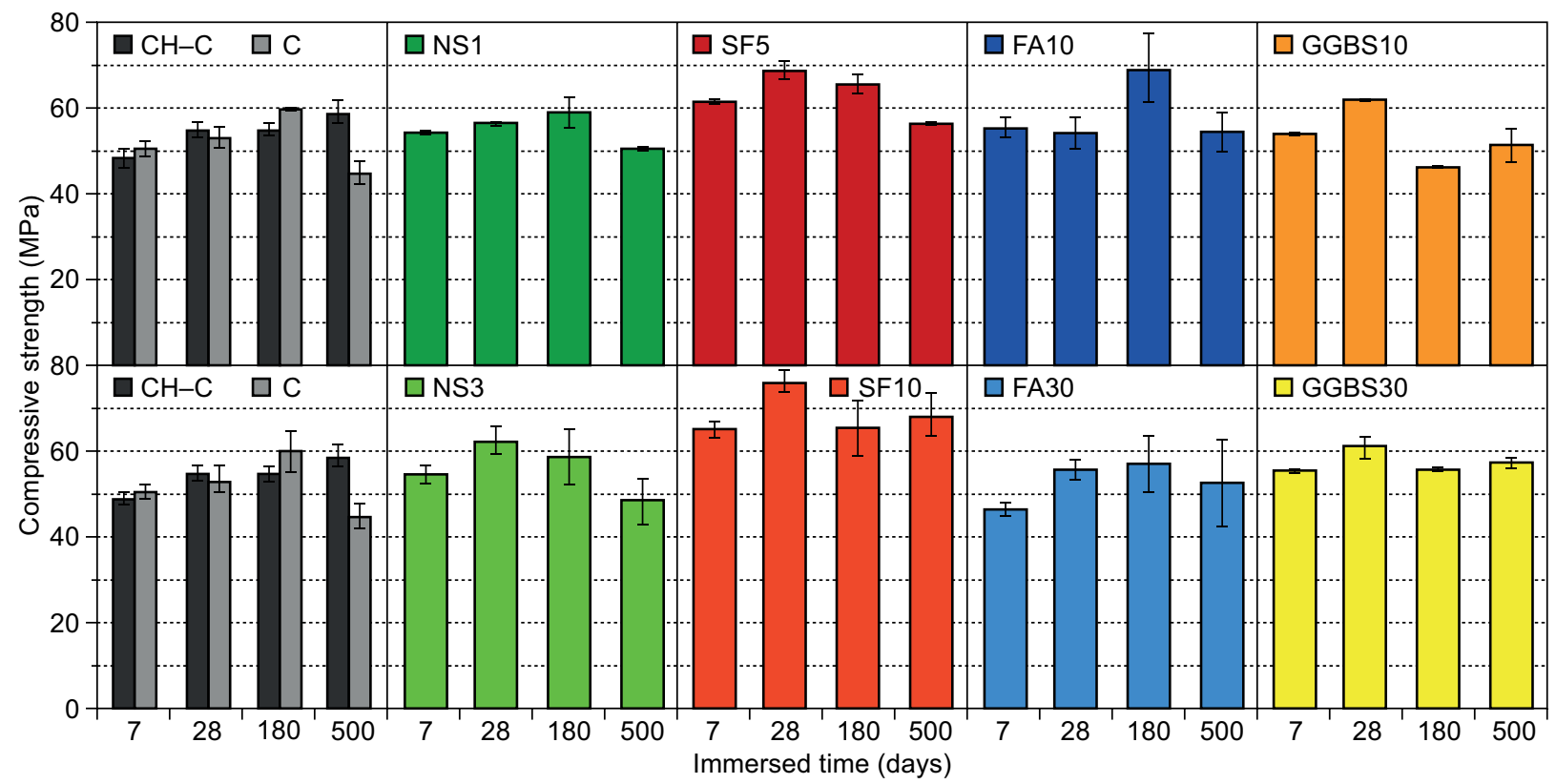

Figure 3. Compressive strength of the cement mortar samples cured in standard conditions for 7 days and then cured in a saturated $\mathrm{Ca}(\mathrm{OH})_{2}$ solution and a 5 wt. $\% \mathrm{Mg}_{2} \mathrm{SO}_{4}$ solution up to 500 days. 
strength at 180 days, due to the weak interface bonding between the unhydrated GGBS and hydrated products, as well as the crystallisation pressure of the erosion pro-
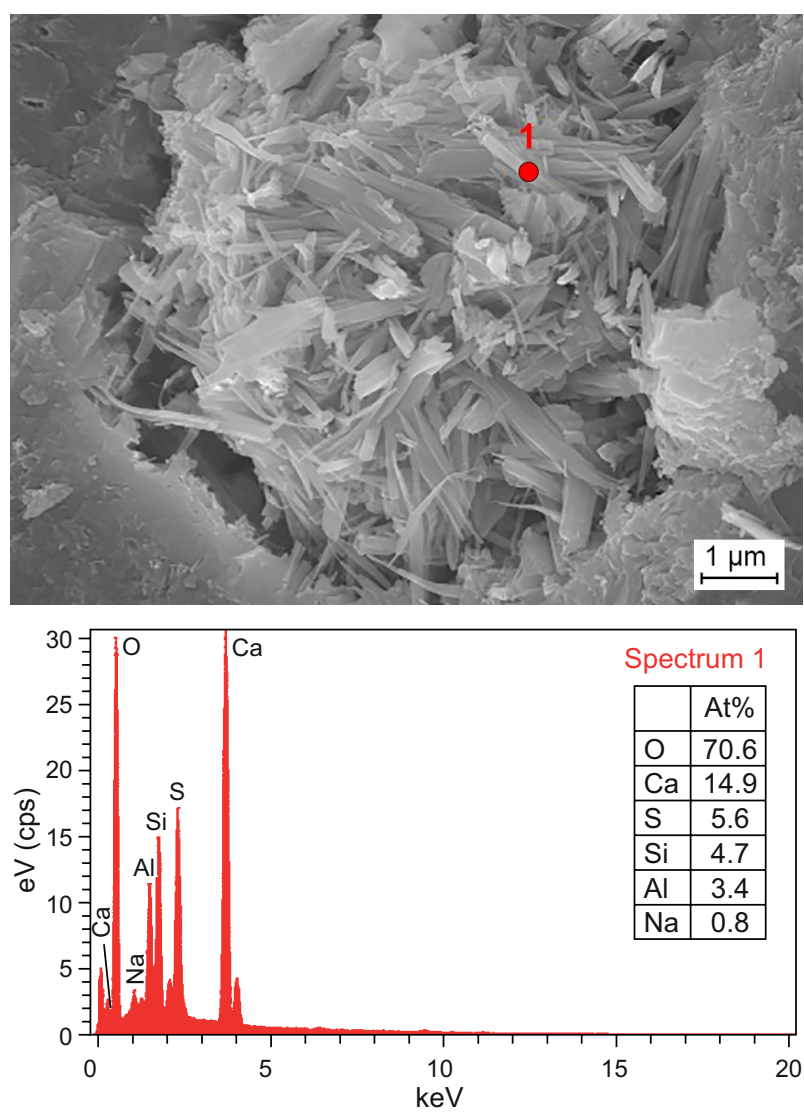

a) ducts [25]. The SEM images and EDS results in Figure 5 show the ettringite and gypsum are formed after the sulfate attack.
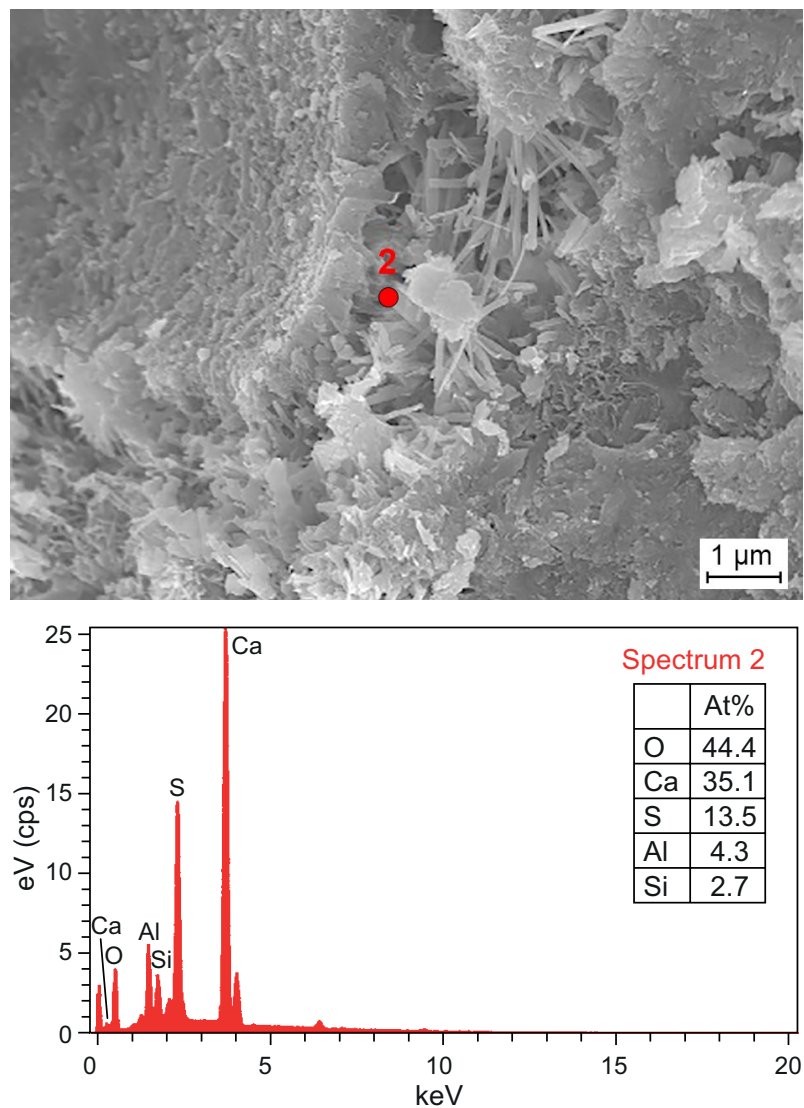

b)

Figure 5. SEM images of the cement paste cured in a 5 wt. $\% \mathrm{Mg}_{2} \mathrm{SO}_{4}$ solution up to 180 days.

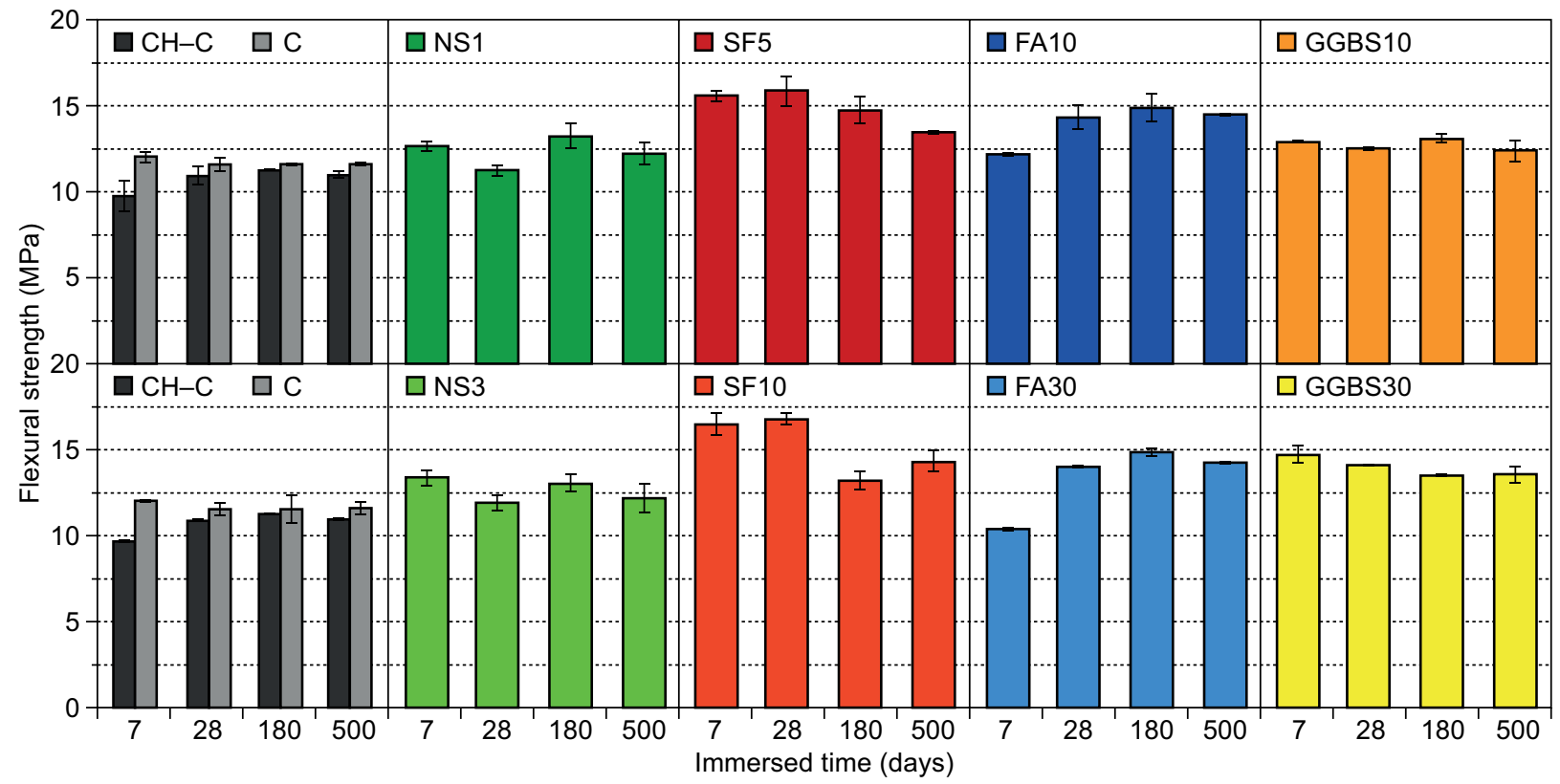

a)

Figure 6. Flexural strength (a) of the cement mortar samples cured in standard conditions for 7 days and then cured in a saturated $\mathrm{Ca}(\mathrm{OH})_{2}$ solution and a 5 wt. $\% \mathrm{Mg}_{2} \mathrm{SO}_{4}$ solution up to 500 days. (Continue on next page) 


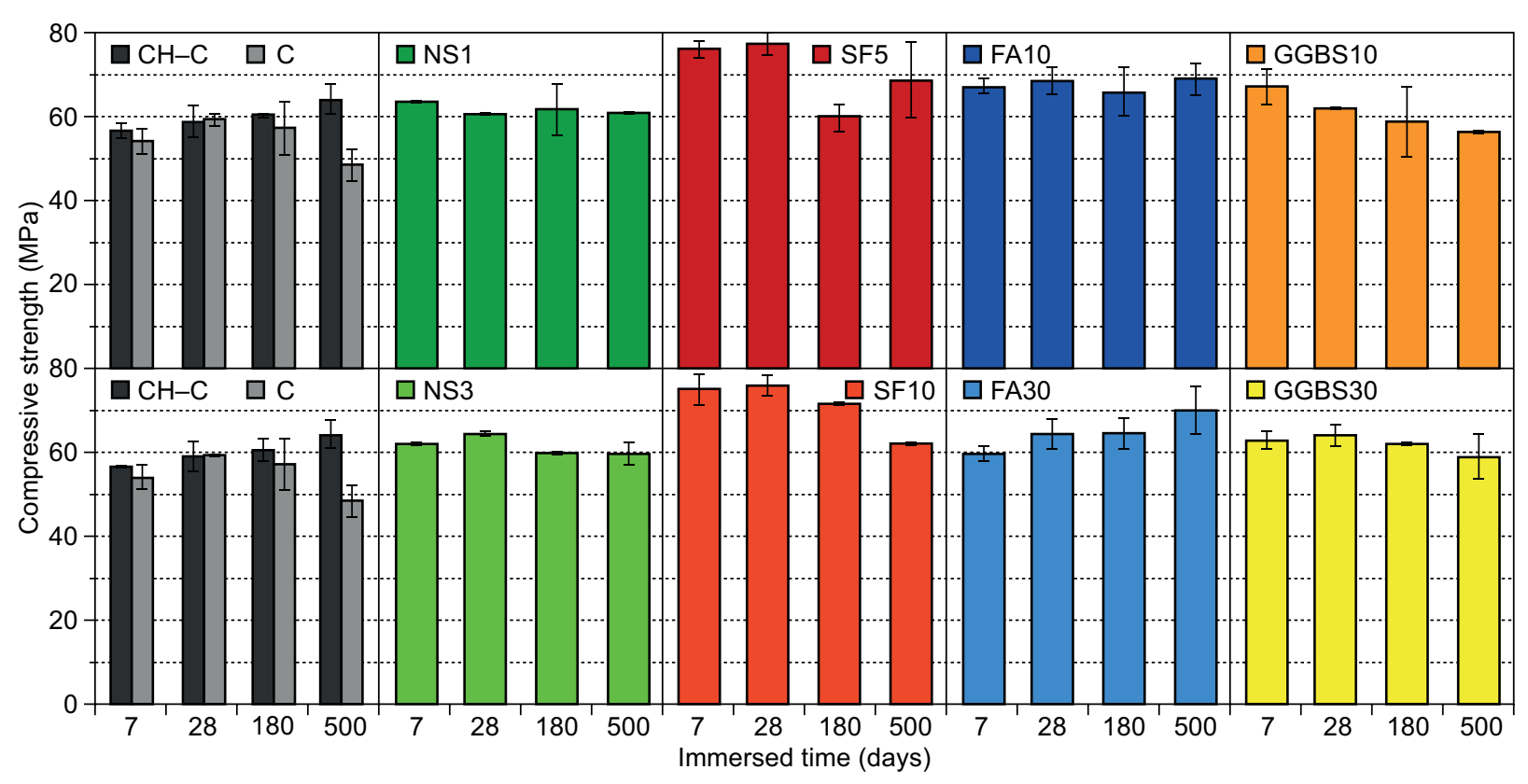

b)

Figure 6. Compressive strength (b) of the cement mortar samples cured in standard conditions for 7 days and then cured in a saturated $\mathrm{Ca}(\mathrm{OH})_{2}$ solution and a 5 wt. $\% \mathrm{Mg}_{2} \mathrm{SO}_{4}$ solution up to 500 days.

The flexural and compressive strengths of the cement mortar exposed to a $5 \mathrm{wt}$ \% magnesium sulfate solution after 28 days of initial curing are shown in Figure 6. Unlike the specimens initially cured for 7 days, the flexural strength of the Group $\mathrm{C}$ mortar specimens under the sulfate attack showed a significant increase compared to the specimens cured in the saturated lime water, but the compressive strength showed a decrease. This might be related to the fracture failure mechanism of the flexural and compressive strengths. The sulfate products, calcium alumina and gypsum, may have had a positive effect on the flexural strength before the specimens were severely damaged.

As the corroding material was continuously under a $\mathrm{MgSO}_{4}$ attack, the flexural strength of NS-blended specimens showed a decreasing trend, then an increasing one and then a decreasing one. The sulfate products formed during the attack process first filled the pores and reached a certain level of micro-crack damage, resulting in a decrease in the strength. When the amount of sulfate attack products continued to increase, these products filled the pores enhancing the strength, and the sulfate attack products reached a certain level of damage again. The SF-blended specimens showed a gradual decrease in the flexural strength because the agglomerated SF particles tended to depolymerise under erosion [25], to aggravate the extension of the cracks and the defects and then to make the flexural strength decrease. The strength of the FA-blended specimens showed a continuous increase because the FA reaction activity was low and the structure was loose, which provided a larger space for the generation of sulfate products. Therefore, the magnesium sulfate attack products during the curing had enough space to grow and the resulting crystallisation pressure was not enough to destroy the matrix, but the filling played a strengthening role [25].

\section{Length change of cement mortars}

The length change of the cement mortar immersed in a 5 wt. $\%$ magnesium sulfate solution after 7 days of initial curing is shown in Figure 7. All the specimens showed expansion at 180 days of immersion. The NSblended specimens showed greater expansion due to the ultrahigh activity of nano-silica $[24,25]$ and the higher crystallisation pressure within the denser structure [25].

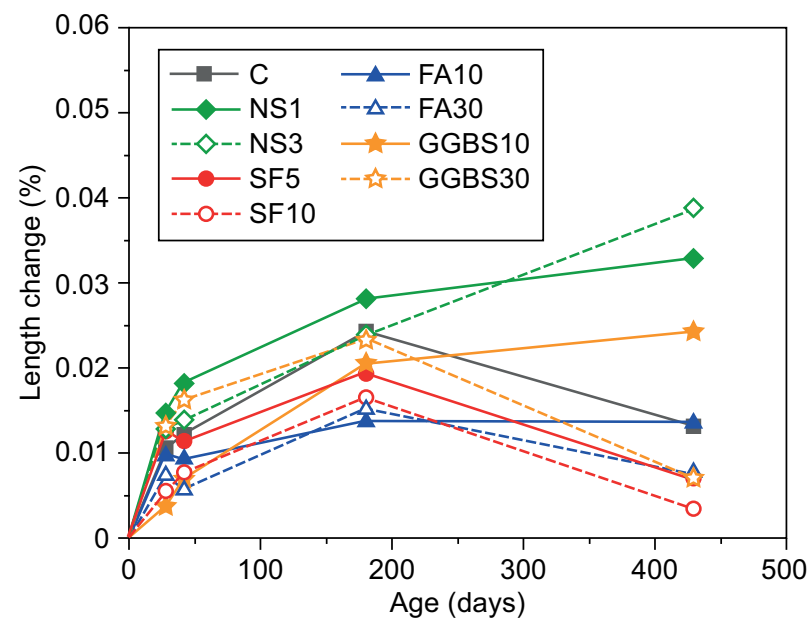

Figure 7. Length change of the cement mortar samples with the initial curing time of 7 days and then cured in a 5 wt. $\% \mathrm{Mg}_{2} \mathrm{SO}_{4}$ solution. 
The GGBS was slightly more reactive than the FA in Figure 2. The pozzolanic reaction of GGBS consumed more $\mathrm{CH}$ required for the erosion product generation and, therefore the length change under erosion was slightly lower than that of Group C. For the SF-blended specimens, the length change was higher than that of the FA specimens and lower than that of the GGBS. Interestingly, the length change of the FA-blended specimens was the lowest, since the lower pozzolanic reactivity of the FA made the cement mortar looser and then had a higher capability of suffering from the expansion of these erosion products, generating less crystallisation pressure and, therefore, less expansion [25]. At immersion for 430 days, the length change of the specimens with the SF, FA, GGBS30 and C groups decreased sharply, while the length change of the specimens with the NS and GGBS10 remained in the process of increasing. This was because the specimens in the SF, FA and $\mathrm{C}$ groups had already been damaged by the 430 days of immersion in the sulfate attack, with internal cracking occurring, releasing some of the crystallisation pressure of the products and, therefore, reducing the expansion rate [25]. The NS-blended specimens were still in an expansive state, indicating that no damage had occurred and that the matrix was still able to withstand the crystallisation pressure, so it could be concluded that the NS-doping improved the resistance of the cement mortar to the crystallisation pressure of the sulfate attack products and that this improved performance could be attributed to its modification with the cement hydration products and the microstructure.

Unlike the specimens at 7 days of initial curing, the specimens with 28 days initial curing firstly showed shrinkage at the early stage of erosion and then gradual expansion at the later stage, as can be seen in Figure 8 . The greatest expansion of the specimens in group $\mathrm{C}$ was observed up to 430 days due to the generation of more

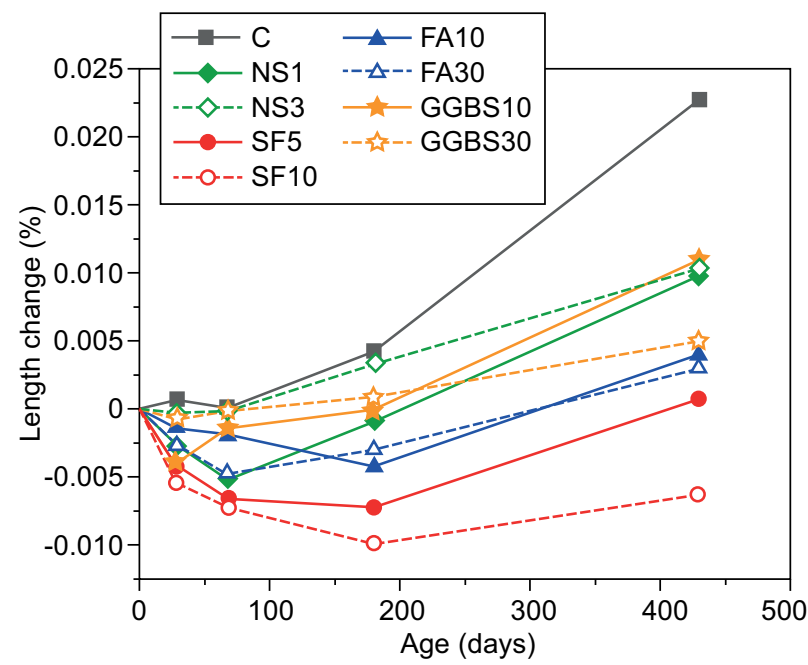

Figure 8. Length change of the cement mortar samples with the initial curing time of 28 days and then cured in a $5 \mathrm{wt}$. \% $\mathrm{Mg}_{2} \mathrm{SO}_{4}$ solution. sulfate attack products and the higher crystallisation pressure [25]. This shrinkage was probably caused by the sulfate-inspired hydration of the SCM blended system and the pozzolanic reaction, where the generated sulfate attack produced less crystalline pressure and the cement hydrated to produce shrinkage, the expansion was not sufficient to compensate for the shrinkage. The specimens in group $\mathrm{C}$ remained expansive. The specimens initially cured for 7 days had a lower maturity in the structural development than the specimens initially cured for 28 days, so that sulfate ingress was easier and more products were produced, to compensate for the shrinkage caused by the sulfate-initiated hydration and showed expansion. For the 28-day initial curing samples, all the specimens still exhibited an expansive state by 430 days of curing. The length change of the NS-blended specimens was lower than that of the C-blended specimens and higher than that of the SF and FA-blended specimens. The lowest expansion of the SF-blended specimens was related to the disintegration of the SF enrichment during the erosion process and the pozzolanic reaction, which released some of the crystallisation pressure and reduces expansion.

\section{CONCLUSIONS}

In this study, the attack resistivity of mortar samples with different amounts of NS, SF, FA, and GGBS was studied by testing the mechanical properties and volume stability of the cement mortars after 7 days and 28 days initial curing time which suffered a $\mathrm{MgSO}_{4}$ attack. The results obtained are as follows:

- The sulfate attack resistivity of the mortar samples mixed with NS or SCMs were improved to varying degrees. The initially 28-day cured samples showed the slightest change in length.

- The pozzolanic reactivity of the SCMs significantly affected the sulfate attack resistivity of the cement mortar. A higher pozzolanic reactivity led to a higher sulfate attack resistivity. More sulfate attack products were produced in the samples prepared with the FA due to the pozzolanic reactivity which was low.

- The higher resistance to crystallisation pressure caused by the sulfate attack was the result of the NS-added samples as no strength loss was observed.

\section{Acknowledgements}

This study is financially supported by the National Natural Science Foundation of China (No. 51802112) and the Natural Science Foundation of Shandong Province (ZR2019BEM034). The funding is also supported by the Opening Project of State Key Laboratory of Green Building Materials. 


\section{REFERENCES}

1. Bassuoni M.T., Nehdi M.L. (2009): Durability of self-consolidating concrete to sulfate attack under combined cyclic environments and flexural loading. Cement and Concrete Research, 39, 206-226. doi: 10.1016/j.cemconres.2008.12. 003

2. Liu Z., Zhang F., Deng D., Xie Y., Long G., Tang X. (2017): Physical sulfate attack on concrete lining - A field case analysis. Case Studies in Construction Materials, 6, 206-212. doi: 10.1016/j.cscm.2017.04.002

3. Geng J., Easterbrook D., Li L.Y., Mo L.W. (2015): The stability of bound chlorides in cement paste with sulfate attack. Cement and Concrete Research, 68, 211-222. doi: 10.1016/j.cemconres.2014.11.010

4. Hossain K.M.A., Lachemi M. (2006): Performance of volcanic ash and pumice based blended cement concrete in mixed sulfate environment. Cement and Concrete Research, $36,1123-1133$. doi: 10.1016/j.cemconres.2006.03.010

5. Skaropoulou A., Tsivilis S., Kakali G., Sharp J.H., Swamy R.N. (2009): Long term behavior of Portland limestone cement mortars exposed to magnesium sulfate attack. Cement and Concrete Composites, 31,628-636. doi: 10.1016/j.cemconcomp.2009.06.003

6. Müllauer W., Beddoe R.E., Heinz D. (2013): Sulfate attack expansion mechanisms. Cement and Concrete Research, 52, 208-215. doi: 10.1016/j.cemconres.2013.07.005

7. Santhanama M., Cohen M. D., Olek J. (2003): Effects of gypsum formation on the performance of cement mortars during external sulfate attack. Cement and Concrete Research, 33, 325-332. doi: 10.1016/S0008-8846(02)00955-9

8. Hime W. G., Mather B. (1999): "Sulfate attack," or is it? Cement and Concrete Research, 29, 789-791. doi: 10.1016/ S0008-8846(99)00068-X

9. Guo Z., Wang Y., Hou P., Shao Y., Zuo X., Li Q., Xie N., Cheng X. (2019): Comparison study on the sulfate attack resistivity of cement-based materials modified with nano$\mathrm{SiO}_{2}$ and conventional SCMs: Mechanical strength and volume stability. Construction and Building Materials, 211, 556-570. doi: 10.1016/j.conbuildmat.2019.03.235

10. Santhanama M., Cohen M. D., Olek J. (2003): Mechanism of sulfate attack: a fresh look: Part 2. Proposed mechanisms. Cement and Concrete Research, 33, 341-346. doi: 10.1016/ S0008-8846(02)00958-4

11. Nehdi M.L., Suleiman A.R., Soliman A.M. (2014): Investigation of concrete exposed to dual sulfate attack. Cement and Concrete Research, 64, 42-53. doi: 10.1016/j.cemconres.2014.06.002

12. Irassar E.F., Maio A.Di. Batic O.R. (1996): Sulfate attack on concrete with mineral admixtures. Cement and Concrete Research, 26, 113-123. doi: 10.1016/0008-8846(95)00195-6

13. Haufe J., Vollpracht A. (2019): Tensile strength of concrete exposed to sulfate attack. Cement and Concrete Research, 116, 81-88. doi: 10.1016/j.cemconres.2018.11.005

14. Bassuoni M.T., Rahman M.M. (2016): Response of concrete to accelerated physical salt attack exposure. Cement and Concrete Research, 79, 395-408. doi: 10.1016/j.cemconres. 2015.02.006

15. Aköz F., Türker F., Koral S., Yüzer N. (1995): Effects of sodium sulfate concentration on the sulfate resistance of mortars with and without silica fume. Cement and Concrete Research, 25, 1360-1368. doi: 10.1016/0008-8846(95) $00128-\mathrm{Y}$
16. Santhanama M., Cohen M. D., Olek J. (2002): Mechanism of sulfate attack: A fresh look 1: Summary of experimental results. Cement and Concrete Research, 32, 915-912. doi: 10.1016/S0008-8846(02)00724-X

17. Hossack A.M., Thomas M.D.A. (2015): The effect of temperature on the rate of sulfate attack of Portland cement blended mortars in $\mathrm{Na}_{2} \mathrm{SO}_{4}$ solution. Cement and Concrete Research, 73, 136-142. doi: 10.1016/j.cemconres.2015.02. 024

18. Kunther W., Lothenbach B., Skibsted J. (2015): Influence of the $\mathrm{Ca} / \mathrm{Si}$ ratio of the $\mathrm{C}-\mathrm{S}-\mathrm{H}$ phase on the interaction with sulfate ions and its impact on the ettringite crystallization pressure. Cement and Concrete Research, 69, 37-49. doi: 10.1016/j.cemconres.2014.12.002

19. Marchand J., Odler I., Skalny J. P. (2002): Sulfate Attack on Concrete, (2002). $1^{\text {st }}$ ed. CRC Press.

20. Zhang Z., Wang Q., Chen H., Zhou Y. (2017): Influence of the initial moist curing time on the sulfate attack resistance of concretes with different binders. Construction and Building Materials, 144, 541-551. doi: 10.1016/j.conbuildmat. 2017.03.235

21. Rupasinghe M., Nicolas R. S, Mendis P., Sofi M., Ngo T. (2017): Investigation of strength and hydration characteristics in nano-silica incorporated cement paste. Cement and Concrete Composites, 80, 17-30. doi: 10.1016/j.cemconcomp.2017.02.011

22. Xu Z., Zhou Z., Du P., Cheng X. (2016): Effects of nanosilica on hydration properties of tricalcium silicate. Construction and Building Materials, 125, 1169-1177. doi: 10.1016/j.conbuildmat.2016.09.003

23. Hou P., Cheng X., Qian J., Zhang R., Cao W., Shah S.P. (2015): Characteristics of surface-treatment of nano- $\mathrm{SiO}_{2}$ on the transport properties of hardened cement pastes with different water-to-cement ratios. Cement and Concrete Composites, 55, 26-33. doi: 10.1016/j.cemconcomp.2014. 07.022

24. Hou P., Qian J., Cheng X., Shah S.P. (2015): Effects of the pozzolanic reactivity of nanoSiO $\mathrm{Si}_{2}$ on cement-based materials. Cement and Concrete Composites, 55, 250-258. doi: 10.1016/j.cemconcomp.2014.09.014

25. Hou P., Guo Z., Li Q., Zhang X., Liu J., Yang S., Cheng X., Kumar R., Srinivasaraonaik B., Singh L.P. (2019): Comparison study on the sulfate attack resistivity of cementbased materials modified with nanoSiO ${ }_{2}$ and normal SCMs: Pore structure and phase composition. Construction and Building Materials, 228, 116764. doi: 10.1016/j.conbuildmat.2019.03.235

26. Supervision, T. (1999): Method of Testing Cements-Determination of Strength. Chinese Code GB, 17671.

27. ASTM, D. (2012): Standard test method for length change of hydraulic-cement mortars exposed to a sulfate solution.

28. Wee T.H., Suryavanshi A.K., Wong S.F., Rahman A.K.M.A. (2000): Sulfate resistance of concrete containing mineral admixtures. ACI Materials Journal,536-549. doi: 10.1016/ S0886-7798(01)00020-7

29. Demir I., Güzelkücük S., Sevim Ö. (2018): Effects of sulfate on cement mortar with hybrid pozzolan substitution. Engineering Science and Technology, an International Journal,21,275-286. doi: 10.1016/j.jestch.2018.04.009 